\title{
Exchanging the baton: the next lap for EJHP
}

\author{
Phil Wiffen
}

With this edition of the European Journal of Hospital Pharmacy (EJHP), I take up the baton so ably carried by Arnold Vulto, the previous Editor-in-Chief. As I pick up this responsibility, I want to pay tribute to Arnold's leadership and wisdom in steering the journal to the current situation. I am aware that Arnold was supported by a number of active members on the associate editor team and I have just returned from a meeting with this able group. I also want to acknowledge the support of a very capable BMJ Group team who have steered me through the processes of journal production.

As I get increasingly into the role I propose to implement my vision for the future of the journal shaped and implemented by the editorial team and the European Association of Hospital Pharmacists (EAHP) board. So what is that vision?

Underpinning everything will be an evidence-based philosophy to ensure that what we publish is explicitly linked to the underpinning evidence whether that is a high-quality methodological approach or even opinion based if that is what we have. This approach enables readers to understand the strength and validity of any recommendations made. I develop this further in my paper on 'Tools not rules' in this edition. Of course the evidence approach has been in the background previously but I intend to make this far more explicit and new approaches will emerge over time. I hope this will encourage an increasing development of the research base for hospital pharmacy which will be essential as resources get tighter. This edition has several articles which pick up on the evidence-based medicine theme to set the tone and there will be more to come. I plan also to explore the importance of audit in documenting what we do in a more effective manner.

Correspondence to Phil Wiffen, Pain Research Unit, Churchill Hospital, Old Road, Oxford OX3 7LE, UK; phil.wiffen@ndcn.ox.ac.uk
I firmly believe that clinical pharmacy is pivotal to the success of hospital pharmacy across Europe and I intend to widen the journal's coverage for clinical pharmacy service delivery and clinical wisdom. Clinical pharmacy is making rapid progress in a number of developing countries, particularly in Asia as governments see its value for the safe and rationale use of medicines. In addition there is good evidence that clinical pharmacy saves lives and saves money. I intend to ensure such developments are not prevented in Europe by a lack of know-how. I am also looking for ways to increase the medicines information content also as such services should be underpinning clinical services. As many medical staff have access to information on the web, there has to be added value from medicines information services and I am keen to encourage papers in this area.

A journal can only survive on the quality and quantity of submitted articles. While commissioned articles have their place and value, I want to encourage a steady stream of good quality submitted papers relevant to hospital pharmacy. A recent survey of attendees at the last EAHP Congress suggests that there are a good number of potential authors within EAHP. I would like to identify ways to turn that potential into EJHP articles. We will initiate a novice authors section where authors will be supported to bring their first peerreviewed article to press. I want to initiate training for authors and peer reviewers so we build capacity in these areas so vital to journal production.

One of the messages that emerged early on in the development of evidence-based medicine was that of keeping up to date with the volume of high-quality literature relevant to our practice. I am therefore looking to establish a regular feature of 'Seen in other journals'. This will enable readers to quickly scan articles that are relevant to their practice without needing to find the original journals.

I would like to increase the editorial skills among pharmacists who are attracted to publishing and will be offering regular guest editor slots. In these a guest editor will be invited to organise a theme for a section of the journal and oversee the development of the articles with a linked editorial. This will be done with the support of the editorial team.

Together with the BMJ Group team we will continue the move towards a more academic look and feel for the journal and you will see changes over the coming months in style and layout. Some of these changes will ensure that the journal maximises its impact factor. We have recently improved the listing in International Pharmacy Abstracts and I am pleased to let you know that the journal will be indexed by Cinahl - more on that in the next edition.

One of the challenges I face is to ensure that the journal has relevance across the whole of Europe. This is not easy and I am looking at ways to improve engagement. I have concerns about whether the country focus is either relevant or helpful given that a particular country section only comes by rota every few years. I am exploring with the editorial board the possibility of an expanded news section with the opportunity for articles relating to developments in a specific country as appropriate.

At the end of the day, the journal needs to be owned and used by its readers. I hope you will get involved by publishing, peer reviewing or taking up a guest editor opportunity. I look forward to the challenges ahead and getting to work with many of you.

\section{Competing interests None.}

Provenance and peer review Commissioned; internally peer reviewed.

Accepted 15 October 2012

European Journal of Hospital Pharmacy

2012;19:495.

doi:10.1136/ejhpharm-2012-000242 